\title{
CONTINUITY MANAGEMENT AND ITS APPLICATION IN INDUSTRIAL ENTERPRISES IN SLOVAKIA
}

\author{
BIELIK - MARETTOVA, M[aria]; MALA, J[ana] \& CERNA, L[ubica]
}

\begin{abstract}
Knowledge is now seen as the most important strategic resource and learning as the strategically most important ability of enterprises and organizations. In the world significantly increases demand for resources and at the same time increases the effort how to integrate and further use these sources. Continuity management is relatively unknown in Slovakia. Although this area of management is relatively new, is its an important part. Ensuring continuity of knowledge with knowledge as a new pillar of organizational success, becomes a fundamental management priority and therefore a fundamental responsibility.

Keywords: continuity management, knowledge, employees, knowledge transfer
\end{abstract}

\section{INTRODUCTION}

"Continuity management is the missing link in knowledge management that will mean significant increases in productivity and knowledge creation cutting-edge thinking regarding knowledge as a corporate asset" (Newton F. Crenshaw).

Effective management of the knowledge asset in any organization requires the integration of two related but different processes that combine synergistically and seamlessly to create a mega process. This mega process of knowledge asset management is analogous in some ways to breathing, which is a process created out of two integrated processes: inhalation and exhalation. One process without the other renders the organism dysfunctional, just as one knowledge process without the other renders the organization dysfunctional. The two knowledge processes that form the mega process of knowledge asset management are [1]:

- Knowledge transfer within the same employee generation (i.e., among current employees),

- Knowledge transfer between employee generations (i.e., from current employees to successor employees).

Knowledge management has traditionally emphasized the first process and largely ignored the second. Because the knowledge transfer between employees' generations was not functional, each generation had to begin by creating their own knowledge base and experiences, thereby significantly slowing down the development organization.

Continuity management specifically addresses the second process: the vertical transfer of job-specific operational knowledge from incumbent to successor employees. Together, the two processes of vertical knowledge transfer between employee generations and horizontal knowledge transfer among current employees ensures the preservation of the organizational knowledge base and its enhancement over time. Years of experience and best practices in the form of institutional knowledge and intellectual capital can be brought to bear on each new problem, enriching the decision-making process and stimulating new and more productive responses [2].

Knowledge transfer among current employees throughout an organization has produced some real successes, but also some impressive failures resulting from the complexity of the task and the frustration it can generate. The primary reason is that continuity management is more manageable than traditional knowledge management because its scope is more limited. Rather than attempting to transfer knowledge across an organization, continuity management transfers knowledge between two people who are performing essentially the same work [2].

\section{REASONS FOR THE IMPLEMENTATION OF CONTINUITY MANAGEMENT}

The heart of any competitive advantage in the Information Age is knowledge, and how deftly it is wielded to gain the upper hand in the turbulent shifts of the marketplace [3].

The emergence of knowledge continuity as a new management function arises quite naturally out of this transformation of knowledge into a key corporate asset. The same forces that made knowledge a scarce resource have made knowledge continuity a new management imperative.

Without some form of continuity management, the crises posed by knowledge discontinuities are irresolvable. But the strategic advantage of continuity management is not just in what it prevents, but in what it creates. By preserving knowledge, continuity management delivers a string of remarkable knowledgerelated improvements that infuse the organization, providing a competitive edge uniquely tailored to the Information Age. The preservation and savvy application of corporate knowledge, competencies, and wisdom that continuity management promises is the most compelling reason for its implementation [4].

These advantages reflect the web of relationships that knowledge both creates and demands, acting 
synergistically with each other to multiply their combined effect.

By implementation of continuity management can enterprise receive many advantages shown in Fig.1.

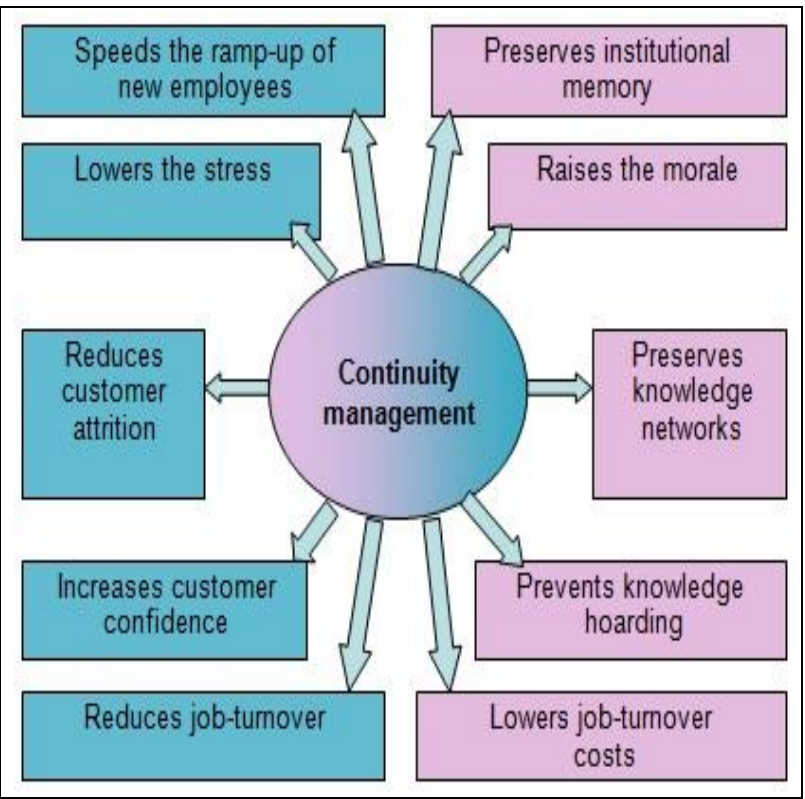

Fig. 1. Advantages of Continuity management implementation

With continuity management, new hires are introduced to the operational knowledge they need from the start, presented in a structured format and at a measured pace that builds competence and confidence. No employee can function adequately without access to the operational knowledge that defines the employee's position. Job-specific operational knowledge is essential for dealing efficiently with recurring situations and effectively with unique situations where standard operating procedures do not apply. Since operational knowledge is based on prior failures as well as prior successes, employees who are aware of past initiatives can exploit their lessons and so avoid repeating what hasn't worked while building on what has. Experience is still the best teacher, but experiences can only teach when they are known [4].

Continuity management maintains the continuity of the network of relationships that powers productivity. When an employee leaves an organization without transferring knowledge of those internal and external contacts that create the knowledge web, the whole web and the whole organization suffers. If some of the nodes are known only to the departing employee, they will be lost forever, especially if they are contacts external to the employee's immediate area of influence or even to the organization itself. Unless knowledge of the network is maintained, the network must be rediscovered or reconstructed,sometimes year after year, by successor employees, at a terrible cost in productivity, effectiveness, and time [5].

The analysis of knowledge needs and knowledge access that is an essential element of continuity management will reveal the existence of knowledge hoarding in an organization.With knowledge hoarding, critical knowledge is centered in - or controlled by-one person and cannot be obtained except through that person. Whether the knowledge hoard is by design (to increase that person's status or power) or as a result of obsolete procedures or past practices, its existence is a threat to the continuity of the organization's knowledge base and productivity [6].

Continuity management also supplies a context in which new hires can place their training, making it more meaningful to them and therefore more effective. Because they understand the training's purpose and can use its lessons immediately, new employees are often more receptive to training, more motivated during the training process, and more enthusiastic about applying what they have learned [7].

Without knowledge continuity, an organization lacks a solid institutional memory from which to grow its knowledge asset. When operational knowledge is preserved from one employee generation to the next, each generation makes the legacy knowledge more valuable to the organization by refining it, updating it, or using it to generate new knowledge. Operational knowledge thus becomes a corporate asset that is reinvested in and by each new employee. New knowledge is created as a return on the investment of that knowledge legacy and is added back to the principal [2].

\section{APPLICATION OF CONTINUITY MANAGEMENT IN INDUSTRIAL ENTERPRISES IN SLOVAKIA}

Knowledge management and its integral part continuity knowledge management play an important role not only in time of economic development as a driver for innovation and increasing competitiveness, but also in time of crisis when there is rising unemployment, skilled workers are leaving and thus also the knowledge they hold [5].

Knowledge leakage influences negatively job cuts in various areas of industry and the associated increase in unemployment. Decrease in the number of employees in industry (B-mining and quarrying, C-industry, Delectricity, gas, steam and air, E-supply of water) in Slovakia is shown in Fig. 2. The difference between the year 2008 and 2009 represents employees -88160 .

Analysis of the state or level of application of the continuity management in industrial enterprises in Slovakia was carried out through a questionnaire survey. The questionnaire contained 21 questions, of which 51 respondents replied, of which were $65 \%$ men and $35 \%$ women.

Of the respondents $70 \%$ were aged 26 to 35 years and in the organization work more than 5 years $65 \%$ of respondents. The questionnaire survey was designed by using available expert resources and surveys focused on knowledge management. On the base of this analysis these assumptions were defined: 
- Enterprises methodically not apply knowledge management,

-In business, it is not sufficient linkage between leaving and new employees.

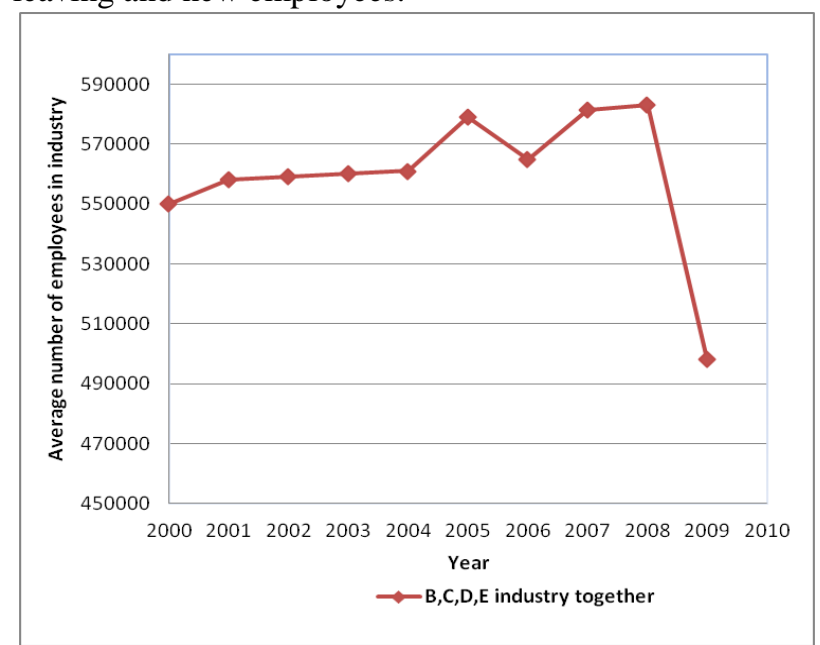

Fig.2. Average number of employees in industry (B, C, D, E) according to clusters of industries s classification of economic activities (NACE $\mathrm{EN})$

On the base of these assumptions, the issues have been established to compile a questionnaire:

- The process of recruitment,

- The process of releasing employees,

- Knowledge processes,

- ICT support.

As an example of the problem area of the adaptation process of new employees, the following question was asked "Which of the methods of education do you use in the adaptation process?" The aim of this question was to identify the methods used in the adaptation process. Each of these methods is another form of knowledge transfer, which is characterized by different intensity of learning and knowledge sharing.

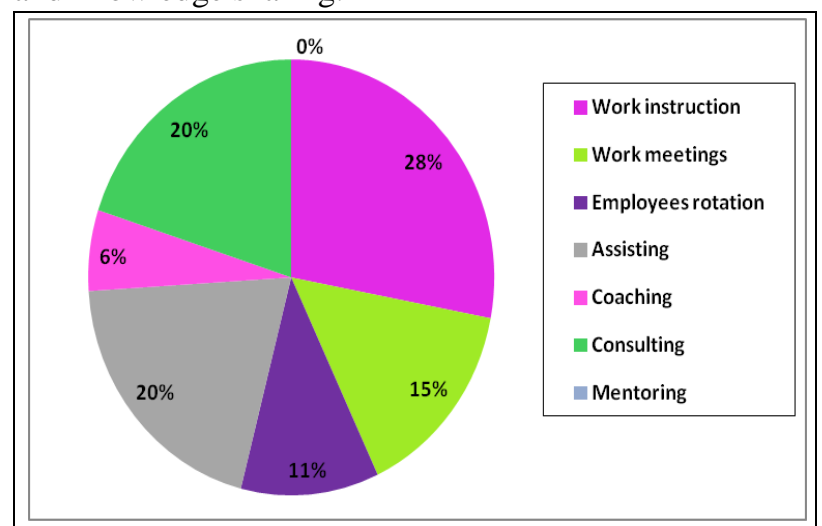

Fig. 3.Graphical evaluation question "Which methods of training do you use in adaptation process?"

On this graph we can see that $28 \%$ of enterprises use in adaptation process instructing, $20 \%$ of enterprises take assisting, the other $20 \%$ of enterprises use the consultation, $15 \%$ of enterprises use meetings, $11 \%$ the employees rotation, $6 \%$ use the coaching and none of the enterprises do not use mentoring.

To knowledge processes were devoted three questions, which is referred to as an example this question "How do you support the knowledge sharing?" This question was designed to identify business' access to knowledge and its sharing. Individual answers are different by levels of support sharing.

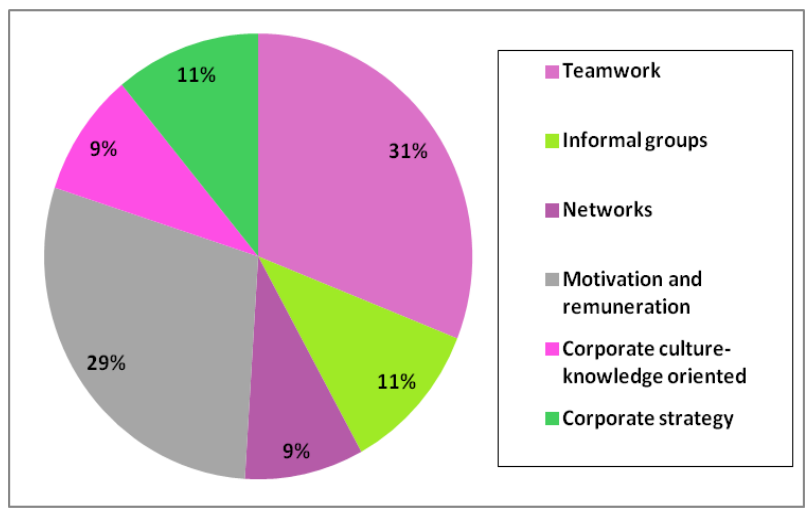

Fig. 4. Graphical evaluation question "How do you support the knowledge sharing?"

In this graph we see that $31 \%$ of participating enterprises use for knowledge sharing support the teamwork, $29 \%$ of enterprises use motivation and remuneration, $11 \%$ of enterprises use for support to informal groups and corporate strategy and $9 \%$ of businesses use networks and corporate culture oriented to knowledge.

Results of the whole survey questionnaire can be summarized as follows:

1. The targets of adaptation process in enterprises are mostly information about products and services and work procedure. In markedly lesser rate about customers. Weak orientation of adaptation process on customer may cause (represents) risk of losing customer,

2. In adaptation process enterprises are focusing mostly on work briefing, assistance and consulting. But none of examined ample is using mentoring,

3. Into adaptation process is most involving boss, similarly colleagues and team,

4. Adaptation process is most rated by assignments,

5. Exit interview is oriented on products and services and work procedures, exactly like adaptation process. In both cases very small attention is paid to customer knowledge,

6. Evaluation of realized assignments and projects is performing by the form of conferences. The best practices and lessons are used not very often,

7. Knowledge in enterprises is mostly the part of processes. Small attention is applied to knowledge like company activities and their innovation support,

8. Knowledge sharing is supported by team work and also with motivation and remuneration, 
9. Information systems are mostly focusing on searching of information. Using of ICT for creating of knowledge is very low.

Results of analyzes approved the assumption that in industry enterpises in field of continuity management dominates short term activities over long term activities. Knowledge is still not perceived like asset that insures company's competitiveness. More attention is applied to knowledge acquiring than to their creation and preserving. Knowledge is considered like passive part of processes. Weak accent is applied on the fact, that owners and creators of knowledge are people. Need of interactions and cooperation is seen just through team interactions and the accent of experiences and knowledge comparing and confrontation is very often neglected.

Results of questionnaire survey indicated on insufficient connectivity between employee hiring process, his classification to working process and employee releasing from working process with company's knowledge processes. From view of continuity management it is needed to enclose this cycle.

Questionnaire survey also indicated on insufficient connectivity between adaptation process and releasing employee from job with customer. In present the orientation on customer is strategic goal for enterpises. Customer classification into centre of this process ensures effective acquiring, processing, preservation and using of customer information that will support customer intelligence with support of analytic tools ICT.

\section{CONCLUSION}

For organization is necessary to think from the beginning about how to catch, keep, share and apply knowledge so, that their creation and innovation could be developed with the best result. The problem is not only loosing of information when employee leaves to pension (or leaves organization from other reasons) but also loosing of his social connections which he used to find answers for question in his field. Creation of social connections is therefore becoming very important part of information keeping, knowledge continuity. Peoples create unofficial connections that fall into creativity and organization influence.

The analysis of asserting the continuity knowledge management in industrial enterprises in Slovakia has shown that in the Slovak enterprises exist components of continuity knowledge management, but not always the knowledge component is present. It is seen mostly in the absence of evaluation of employee's knowledge and its storing for further usage. It can be also said that there is a connection between the enterprise culture and sharing of knowledge. It means that the enterprise culture influences who shares knowlege with the new employees in the adaptation process. The analysis has also shown the fact that in the enterprises there is not a sufficient connection between the knowledge that are needed to be stored and that are needed to be delivered in the adaptation process.
If we want to solve effectively the knowledge management in an enterprise, we need to have a very concrete idea of the knowledge carrier, because these persons are usually not only the object but in many concrete cases also subjects of the knowledge control in the enterprise. The release of the knowledge potention, hidden in the heads of our employees, has an important influence on the motivation of the employees, can be individually or within the team work.

\section{REFERENCES}

[1] Beazley H., Boenisch J., Harden D.: Preserving Corporate Knowledge And Productivity When Employees Leave. Canada: John Wiley \& Sons, Inc., 2002. ISBN 0-471-21906-1

[2] Bergeron B.: ESSENTIALS of Knowledge Management. John Wiley \& Sons, Inc., 2003. ISBN 0-471-28113-1

[3] Šujanová J., Rešetová K., Výboch J.: Information management. Bratislava: STU, 2007. ISBN 978-80-227-2602-3

[4] Robertson, M. - Swan, J. 2003. Control - what control: Culture and ambiguity within a knowledge intensive firm. In: Journal of Management Studies, 2003, Vol. 40(4), s. 831-858

[5] Karreman, D. - Alveson, M. 2004. Cages in tandem: Management control, social identity, and identification in a knowledgeintensive firm. In: Organizational Journlal, 2004, Vol. 11(1), s. 149-175

[6] Barsh, J. 2008. Innovative Management: A Conversation with Gary Hamel and Lowell Bryan. In: The McKinsey Quarterly, 2008, N. 1

[7] Rusanow, G. 2006. Global Law Firm Knowledge Management Survey.[cit. 2010-10-15] available online :<http://www.llrx.com /node/1705/print > 